Revista de Economia Política, vol. 33, $n^{o} 3$ (132), pp. 463-485, julho-setembro/2013

\title{
Desindustrialização e comércio exterior: evidências recentes para o Brasil
}

\author{
ANDRÉ MOREIRA CUNHA \\ MARCOS TADEU CAPUTI LELIS \\ FLAVIO BENEVETT FLIGENSPAN*
}

De-industrialization and foreign trade: recent evidences to Brazil. This paper analyses the behavior of the Brazilian manufacturing sector during the 2000's. We test the hypothesis of early de-industrialization induced by foreign trade. Our results show a mixed picture: although we showed signs of early de-industrialization induced by foreign trade, at the same time, we found evidence that Brazilian entrepreneurs have reduced manufacturing exports during internal market boom between 2004 and 2010. This fact determines the deterioration of trade balance of the manufacturing sector and justifies worries on long-term perspectives for Brazilian economy.

Keywords: Early de-industrialization; manufacturing sector; Brazilian economy. JEL Classification: O14; F43.

\section{INTRODUÇÃO}

Nos últimos anos, o bom desempenho geral da economia brasileira não foi capaz de mitigar as preocupações em torno da capacidade da indústria manufatureira em se manter competitiva. A recuperação da produção e do emprego, especialmente em 2010, contrasta com os crescentes déficits no comércio internacional de manufaturados (IEDI, 2011; Ministério da Fazenda, 2010). Esta questão, em

\footnotetext{
* Respectivamente, Professor do Departamento de Economia da Universidade Federal do Rio Grande do Sul-UFRGS e Pesquisador do CNPq. E-mail: andre.cunha@ufrgs.br; Professor da Unisinos e Coordenador da Unidade de Inteligência Comercial e Competitiva da APEX-Brasil.E-mail: mcaputi@uol.com. br; Professor do Departamento de Economia da UFRGS. E-mail: fli@ufrgs.br. Submetido: 4/Abril/2011; Aprovado: 17/outubro/2012.
} 
particular, está no centro dos debates (Bresser-Pereira, 2010; Oreiro e Feijó, 2010; Fishlow e Bacha, 2010): estaria o Brasil caminhando para um processo de desindustrialização precoce, evidenciado, entre outros fatores, pela perda da capacidade de concorrer com a produção manufatureira importada? Seria este fato o resultado da "doença holandesa"? A "reprimarização" (ou "commoditização") da pauta de exportações estaria evidenciando tais dinâmicas? A literatura ${ }^{1}$ define desindustrialização a partir da queda persistente na produção e/ou no emprego industrial com respeito à produção e emprego totais, respectivamente, bem como à deterioração do comércio internacional da indústria de transformação. Este processo pode estar associado a causas "virtuosas", como o amadurecimento de uma economia, em que a maior produtividade da indústria reduziria custos e o valor da produção com respeito ao restante da economia. Neste caso, ao atingir elevados níveis de renda per capita, é natural que o setor de serviços adquira maior participação no PIB e na geração de emprego. No entanto, o fenômeno pode também estar associado a razões perversas de desempenho medíocre de uma economia, geralmente relacionado aos problemas de gestão macroeconômica ${ }^{2}$. A quebra das cadeias de produção e o deslocamento de parcelas da produção industrial para os países em desenvolvimento também teria contribuído para a desindustrialização nas economias maduras. Estas, por sua vez, estariam se especializando em produtos e serviços de maior valor adicionado.

Oreiro e Feijó (2010) apresentam a resenha do debate recente no Brasil, bem como as dificuldades metodológicas de se obterem séries estatísticas de longo prazo que permitam avaliar a perda de dinamismo da indústria no caso brasileiro. Estes autores esclarecem as diferenças conceituais entre desindustrialização, reprimarização da pauta de exportações e "doença holandesa". Neste último caso, a apreciação da moeda nacional por efeito da valorização das commodities no mercado internacional induziria à desindustrialização. Para Oreiro e Feijó (2010), o balanço das evidências empíricas apontaria para a existência de preocupante perda de dinamismo da indústria. Por outro lado, Bonelli e Pessôa (2010) sinalizam que, do ponto de vista da produção, da evolução do emprego e produtividade e, principalmente, dos investimentos, não haveria evidências inequívocas de desindustrialização no Brasil. Todavia, os autores alertam que, no plano internacional, a indústria perde participação relativa na renda como resultado do progresso tecnológico, dos efeitos sobre o consumo da elevação da renda per capita (Lei de Engel) e da maior internacionalização das economias, dentre outros fatores.

No caso brasileiro recente, o convívio simultâneo de produção industrial crescente com efeitos positivos sobre o emprego e os salários, de um lado, com déficits

\footnotetext{
${ }^{1}$ As referências estão em Rowthorn e Ramaswany (1999), Bresser-Pereira (2010) e Oreiro e Feijó (2010).

${ }^{2}$ Palma (2007), seguindo a tradição kaldoriana (Kaldor, 1966 e 1967), identifica o caráter precoce da desindustrialização em várias economias periféricas, especialmente na América Latina. Tal precocidade se explicitaria sempre que o nível efetivo de participação da indústria no PIB se revelar inferior ao esperado para o nível de renda per capita de cada economia.
} 
comerciais na pauta de manufaturados, de outro, tem tornado a discussão sobre o futuro da indústria ainda mais candente. Nesse contexto, o presente artigo tem por objetivo analisar o comportamento das exportações e importações do Brasil, enfatizando o setor manufatureiro nos anos 2000. São apresentados indicadores de comércio exterior e produção doméstica da economia brasileira com periodicidade pouco explorada na literatura ${ }^{3}$, quais sejam, a produção industrial, o coeficiente de exportações e o coeficiente de penetração das importações, de acordo com a Classificação Nacional de Atividade Econômica (CNAE), versão 1.0, com detalhamento em dois e três dígitos.

Nossa hipótese central é que, diante da aceleração do crescimento da demanda doméstica e com a redução da rentabilidade das exportações derivada do Real excessivamente sobrevalorizado ${ }^{4}$, a indústria está reproduzindo um padrão histórico de reação, direcionando parcelas crescentes de sua produção para o mercado interno. Nossos resultados apontam que, de fato, houve aumento no coeficiente de penetração de importações e queda no coeficiente de exportação das manufaturas no período analisado. Por meio da estimação de um modelo de correção de erros vetorial (VEC), relacionando as séries estatísticas de comércio exterior de manufaturas, produção industrial e taxa de câmbio, constatou-se que o aumento do nível de atividade no Brasil está vinculado à perda de dinamismo das exportações de manufaturas e ao aumento das importações de bens industrializados. Vale dizer, a velha hipótese de que o saldo comercial brasileiro tende a se deteriorar quando há expansão do nível de atividade da economia encontra respaldo em nossas evidências. Neste sentido, procura-se contribuir com uma discussão que é central para o pensamento desenvolvimentista latino-americano, qual seja, a recorrência de restrições externas ao crescimento ${ }^{5}$ e a importância de se manter uma estrutura produtiva complexa e integrada como forma de se obterem maiores graus de autonomia no processo de desenvolvimento.

\section{O DESEMPENHO DO COMÉRCIO EXTERIOR E DA PRODUÇÃO INDUSTRIAL}

Conforme reportado pelo IEDI (2011), a balança comercial da indústria de transformação passou de um superávit médio de mais de US\$ 30 bilhões, no biênio 2005-2006, para déficits crescentes. Em 2009, tal déficit atingiu US\$ 8,5 bilhões e,

\footnotetext{
${ }^{3}$ No caso brasileiro são usualmente utilizados dados trimestrais ou anuais. Ver, por exemplo, Moreira e Puga (2001), Levy e Serra (2002), Nassif (2008), Bonelli e Pessôa (2010) e Oreiro e Feijó (2010).

${ }^{4}$ Nassif, Feijó e Araújo (2011) analisam a literatura pertinente e mostram que o Real tem se mantido sobrevalorizado no período aqui analisado.

${ }^{5}$ Michel e Carvalho (2009) organizam coletânea de trabalhos que resgatam este tema. Assumimos aqui o debate herdado dos trabalhos clássicos da CEPAL, de Prebisch (1950), Furtado (2009), Tavares (1973), dentre outros. Os trabalhos de Castro e Souza (1985) e Carneiro (2002) são exemplos desta tradição para os debates dos anos 1980 e 1990.
} 
em 2010, US\$ 34,8 bilhões, a despeito da expansão das exportações. Esta situação contrasta com a verificada entre 2002 e 2005 , quando a produção física da indústria de transformação cresceu $14 \%$, enquanto o saldo comercial deste segmento passava de um superávit de US\$ 6,9 bilhões para US\$ 31,1 bilhões. Desde então, tais saldos vêm recuando rapidamente, enquanto a produção se recuperava dos efeitos da crise financeira global. Esta mesma fonte reporta que o saldo comercial negativo é mais forte nos setores intensivos em tecnologia. Por sua vez, o Ministério da Fazenda (2010) reporta que 62,5\% das exportações brasileiras correspondem a commodities, estas entendidas como o somatório de produtos básicos, semi manufaturados e dez produtos manufaturados.

A premissa principal deste trabalho é que a avaliação do desempenho do comércio exterior da indústria manufatureira deve partir de duas constatações básicas: (i) a economia brasileira experimentou, entre 2004 e 2008, o ciclo mais longo de expansão desde os anos 1970, com destaque para o comportamento dos investimentos; e (ii) a economia mundial está atravessando transformações estruturais derivadas da ascensão das economias emergentes (Canuto e Giugale, 2010; Fishlow e Bacha, 2010). No que se refere ao desempenho mais geral da economia brasileira, cabe observar que, desde meados de 2004, verificou-se um quadro muito positivo segundo o qual emergiu um período de crescimento ininterrupto do consumo e dos investimentos, o que garantiu a elevação da produção em um contexto de inflação moderada, redução dos desequilíbrios fiscais e externos e melhorias persistentes nos indicadores sociais e distributivos. O efeito-contágio da crise financeira global se fez sentir com particular intensidade na indústria. Todavia, já em 2010, os níveis de produção e utilização da capacidade atingiram patamares mais elevados que antes da crise (Ministério da Fazenda, 2010).

Em uma perspectiva de longo prazo, economias em desenvolvimento tendem em geral a se defrontar com restrições externas ao amadurecimento pleno de suas estruturas produtivas. $\mathrm{O}$ processo de industrialização mostra-se contraditório, na medida em que a superação do atraso por meio da internalização de setores produtivos mais complexos, porque intensivos em capital, tecnologia, capacidades organizacionais etc., cria pressões significativas sobre o balanço de pagamentos. A importação de bens industriais cresce de forma mais intensa do que a renda doméstica e do que as exportações de produtos tradicionais, geralmente intensivos em recursos naturais. A atração de capital estrangeiro, gerando ciclos de endividamento e/ou perda de controle sobre os centros decisórios estratégicos, torna-se um recurso virtualmente universal. A superação do subdesenvolvimento, portanto, passa, também, pela capacidade de administrar uma dinâmica instável de amadurecimento da estrutura produtiva rumo a setores mais complexos, garantido a capacidade de geração de divisas por meio das exportações de manufaturas. O Brasil enfrentou tais dilemas. Todavia, depois da crise da dívida externa, no começo dos anos 1980, verificou-se um longo ciclo de baixo crescimento e instabilidade macroeconômica. No começo dos anos 1990, ganhou corpo a visão de que as reformas estruturais liberalizantes determinariam um novo padrão de desenvolvimento. $\mathrm{O}$ setor produtivo teve de se ajustar a tais mutações e logrou sobreviver aos anos mais difíceis.

\section{"Doença holandesa” e os saldos comerciais}


Nossa análise parte do movimento tendencial do saldo comercial total (BC) ${ }^{6}$ para o período 1990-2010. O Gráfico 1 identifica a tendência e o valor observado do saldo da BC, já com as irregularidades e as quebras de tendência demarcadas. Percebe-se a queda pronunciada na tendência estimada quando da adoção do Plano Real, em 1994, e sua elevação significativa entre 2002 e 2006. Distinguem-se duas fortes alterações no nível da tendência estimada do saldo da BC. A primeira ocorre no mês de novembro de 1994, decorrente do regime cambial e da dinâmica de liberalização comercial proposta no Plano Real, representando uma quebra de nível da tendência. Já a segunda quebra ocorreu em setembro de 2002, quando a elevação da tendência em mais de US\$ 1,1 bilhão está associada às vendas do complexo soja e de minérios para a economia chinesa.

Gráfico 1: Valores observados e tendência do saldo da balança comercial do Brasil, em US\$ milhões — janeiro de 1990 a setembro de 2010

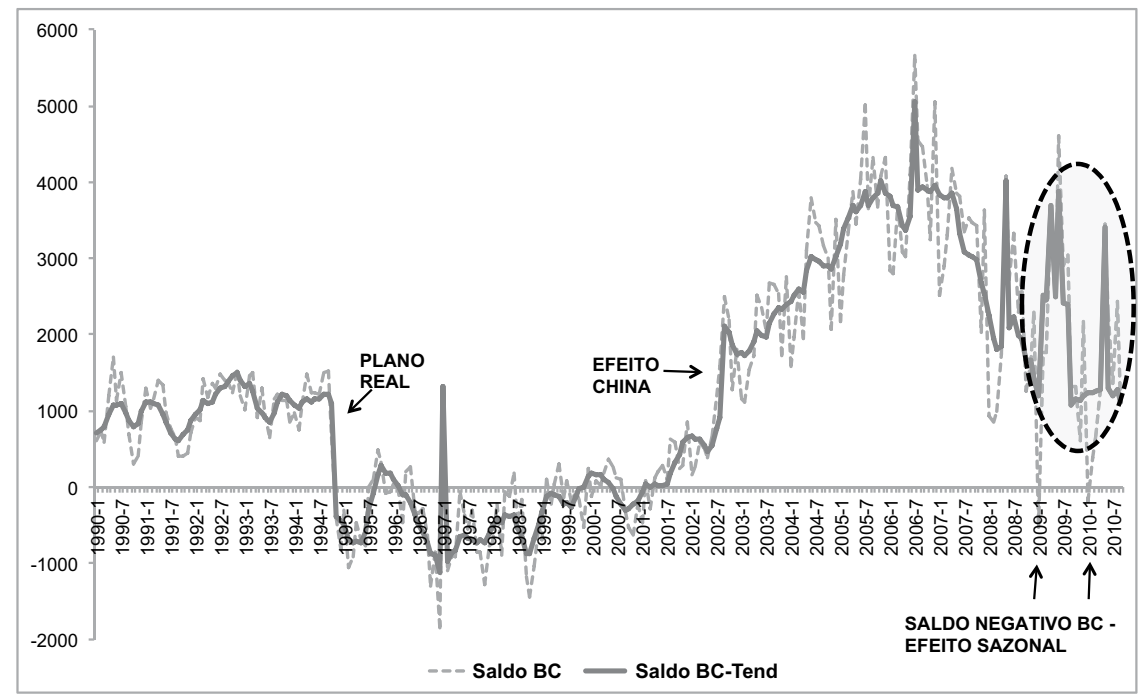

Fonte de dados brutos: Banco Central do Brasil.

\footnotetext{
${ }^{6}$ A metodologia econométrica aplicada na definição desta tendência aborda modelos de série de tempo estrutural univariado decomposto em componentes não observados: (i) tendência; (ii) sazonalidade; (iii) ciclos; e (iv) irregularidades (choques). Tal metodologia permite alterações ao longo do tempo nos quatro componentes não observados. Evidenciam-se, dessa forma, mudanças no comportamento da tendência estimada a partir de quebras estruturais de nível ou de declividade e, ao mesmo tempo, nos outros componentes não observados. Para maiores detalhes, ver Harvey (1989) e Commandeur e Koopman (2007).
} 
A comparação da média estimada da tendência do saldo da BC, após os efeitos da crise econômica de 2009, com esse mesmo indicador no período que se inicia no mês de janeiro de 1990 até a quebra de nível da tendência provocada pelo Plano Real, indica um valor 50\% maior que o encontrado no início da década de 1990, sendo que a atual conjuntura de crescimento da demanda interna é significativamente mais favorável. Nota-se, também, que há dois meses em que o saldo observado da BC ficou deficitário - janeiro de 2009 e de 2010 - o que é explicado, principalmente, pela sazonalidade do saldo da $\mathrm{BC}^{7}$.

Se a $\mathrm{BC}$ tem tido seu comportamento favorável em função dos produtos considerados básicos, cabe analisar o saldo obtido pela indústria de transformação brasileira (IT). Propõem-se, então, duas agregações setoriais diferentes. A primeira leva em consideração o total da indústria de transformação sem o setor de alimentos e bebidas (IT-AB). Essa estrutura é construída pelo fato de o setor de alimentos e bebidas caracterizar-se pela constituição de grandes superávits comerciais. Dessa maneira, ao excluir esse setor, tem-se um panorama mais exigente ao saldo da balança comercial da indústria de transformação. A segunda agregação considera o saldo da balança comercial de toda a IT. A metodologia de análise das séries dos saldos comerciais da IT-AB e IT é a mesma definida para o saldo da BC, com modelos de série de tempo estrutural univariado decomposto em componentes não observados (gráfico 2).

Observa-se que, depois de 2006, há uma alteração na tendência das duas séries estimadas - saldos da IT e da IT-AB —, caracterizando deterioração e déficits. Isto coincide com o período de crescimento mais acelerado com estabilidade. Aparece aqui o velho dilema do crescimento com restrição externa derivada da piora nos saldos comerciais, em que o crescimento da renda vem associado à piora nas contas externas. É importante lembrar, também, que esse momento coincide com a trajetória de apreciação da moeda nacional. Depois de 2006, o crescimento da demanda interna teve peso significativo na alteração da trajetória dos saldos da BC da IT e da IT-AB.

Ainda observando o Gráfico 2, foram identificadas duas quebras de nível na tendência estimada do saldo da BC de IT-AB nos meses de novembro de 2008 e fevereiro de 2009. É oportuno lembrar que a crise econômica de 2009 instalou-se na economia brasileira no último trimestre de 2008. Após aquelas quebras, a trajetória do saldo comercial da IT e da IT-AB retorna ao seu comportamento pré-crise, com a mesma dinâmica observada desde o terceiro trimestre de 2006.

\footnotetext{
${ }^{7}$ A sazonalidade estimada do saldo da BC mostra variações mais intensas após 2002 - não por acaso o ano da quebra de nível do saldo da BC, provocada pelas alterações das exportações brasileiras de commodities à China -, haja vista a elevação da participação dos produtos intensivos em recursos naturais e primários na pauta de exportações do país (Canuto e Giugale, 2010). O gráfico da sazonalidade pode ser solicitado aos autores por e-mail.
} 
Gráfico 2: Valores observados e tendências dos saldos comerciais da indústria de transformação brasileira sem alimentos e bebidas (IT-AB) e da indústria de transformação total (IT), em US\$ milhões — janeiro de 2005 a setembro de 2010

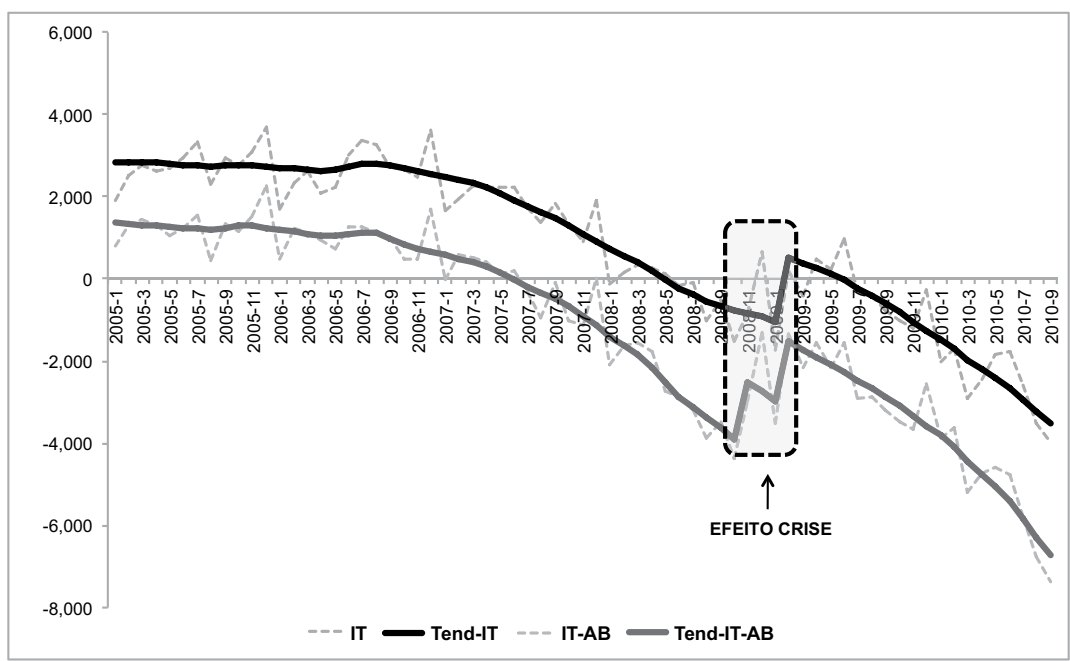

Fonte de dados brutos: Ministério do Desenvolvimento, Indústria e Comércio Exterior (MDIC).

\section{Coeficientes de orientação externa}

A elevação dos déficits comerciais da IT e da IT-AB tem alimentado preocupações em torno da desindustrialização da economia brasileira via comércio exterior (IEDI, 2011; Bresser-Pereira, 2010). A presente seção aborda esse tema, contribuindo com evidências empíricas potencialmente inéditas, através do cruzamento de informações de comércio exterior e valor da produção. Para tanto, foram construídos dois indicadores: o coeficiente de exportações e o índice de penetração das importações, com periodicidade mensal, respeitando a estrutura da CNAE $1.0^{8}$. O coeficiente de exportação mostra a relação entre exportações e valor da produção, sendo definido pela seguinte expressão:

$$
C E X_{t}^{i}=\frac{E X_{t}^{i}}{V P_{t}^{i}}
$$

Onde: $C E X_{t}^{i}=$ coeficiente de exportações do setor i no tempo t; $E X_{t}^{i}=$ valor das exportações do setor i no tempo t; $V P_{t}^{i}=$ valor da produção do setor i no tempo t.

Já o índice de penetração das importações define a parcela do consumo aparente, ou seja, a oferta interna da economia, suprida pelas importações. Neste sentido, escreve-se a definição:

\footnotetext{
${ }^{8}$ Séries produzidas pela Apex-Brasil.
} 


$$
\begin{aligned}
& C A_{t}^{i}=V P_{t}^{i}-E X_{t}^{i}+I M_{t}^{i} \\
& I I M_{t}^{i}=\frac{I M_{t}^{i}}{C A_{t}^{i}}
\end{aligned}
$$

Sendo, $C A_{t}^{i}=$ consumo aparente no tempo $\mathrm{t}$ do setor $\mathrm{i} ; M_{i}^{t}=$ importações no tempo $t$ do setor i; $I I M_{t}^{i}=$ índice de penetração das importações no tempo t do setor i.

Cabe destacar duas dificuldades no cômputo destes indicadores. A primeira delas diz respeito à periodicidade da análise, que aqui toma a forma mensal. Com isso, tem-se a presença de um componente sazonal bastante significativo para alguns setores. Já a segunda dificuldade passa pela necessidade de se computar as exportações e as importações em moeda local, objetivando a comparação com o valor da produção nacional. Com efeito, numa conjuntura de forte valorização do Real em frente ao dólar estadunidense, o $I I M_{t}^{i}$ e o $C E X_{t}^{i}$ apresentam uma dinâmica que os torna baixos apenas pelo movimento de conversão monetária. Uma maneira de minimizar esses dois inconvenientes metodológicos se dá por meio do emprego dos valores das tendências estimadas das séries originais ( $E X_{t}^{i}, I M_{i}^{t} \mathrm{e} V P_{t}^{i}$ ), ao passo que o coeficiente de exportações e o índice de penetração das importações são computados a partir dos valores dessas tendências. O método econométrico aplicado é novamente o de modelos univariados decompostos em componentes não observados. Assim, é possível perceber as quebras estruturais e as irregularidades das séries estudadas, excluindo o efeito sazonalidade. Continua-se utilizando a mesma composição anterior, ou seja, a indústria de transformação sem os setores de alimentos e bebidas (IT-AB).

Definidas a metodologia e a agregação propostas para o cômputo do $I I M_{t}^{i}$ e o $C E X_{t}^{i}$, o Gráfico 3 mostra a trajetória desses dois indicadores para a IT-AB 9

Ao observar os movimentos mais gerais dos dois indicadores especificados na figura anterior, tem-se uma diminuição no $C E X_{t}^{i}$ e um aumento no $I I M_{t}^{i}$. O $C E X_{t}^{i}$ mostrava um movimento de flutuação em torno de $20 \%$ até o mês de outubro de 2006. No ano seguinte, porém, constata-se nítida tendência de diminuição no $C E X_{t}^{i}$ da IT-AB. Não é por acaso que esse deslocamento ocorre no momento em que se apresenta uma conjuntura mais robusta de expansão do consumo das famílias e do investimento na economia brasileira (Ministério da Fazenda, 2010). Observa-se, também, que após os efeitos da crise econômica de 2009 o $C E X_{t}^{i}$ se estabiliza num patamar de $14 \%$. Já em relação ao $I I M_{t}^{i}$ da IT-AB, tem-se estabilidade até junho de 2006, com valor em 17\%. Um ano e meio depois, em dezembro de 2007, esse indicador altera-se em apenas 1 ponto percentual. Após esse período de es-

\footnotetext{
${ }^{9}$ Duas irregularidades se destacam. A primeira se deve à greve dos auditores fiscais da Receita Federal ocorrida em março de 2008 e a outra acontece exatamente nos meses de forte depreciação da moeda nacional em frente ao dólar estadunidense, decorrente das expectativas criadas pela crise econômica de 2009. É importante, portanto, desconsiderar essas dinâmicas quando se analisa a trajetória do $I I M_{t}^{i}$ e do $C E X_{t}^{i}$.
} 
Gráfico 3: Tendência estimada do coeficiente de exportações e do índice de penetração das importações na indústria de transformação brasileira sem alimentos e bebidas (IT-AB), em \% — janeiro de 2005 até agosto de 2010

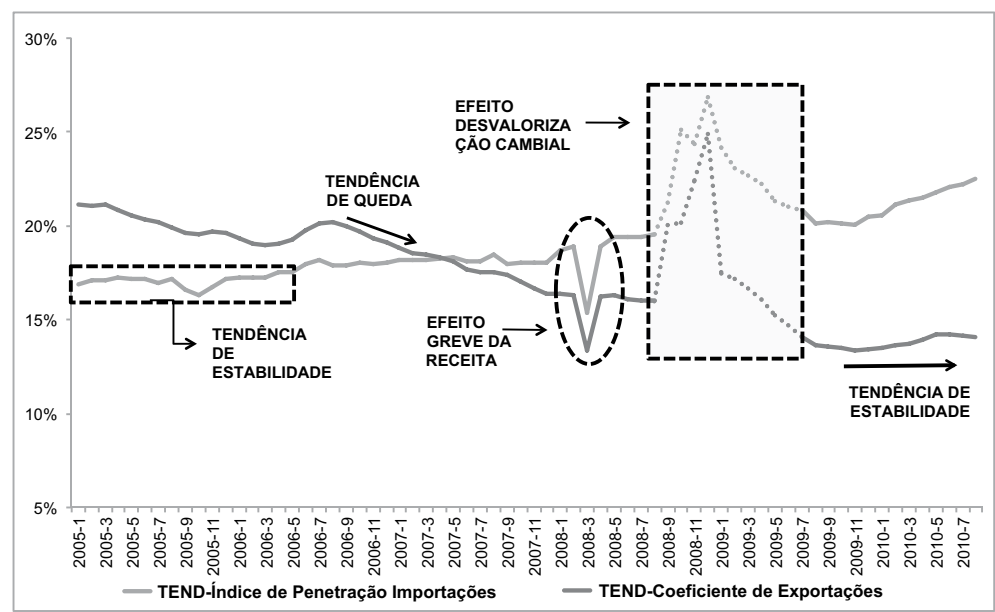

Fonte de dados brutos: Ministério do Desenvolvimento, Indústria e Comércio Exterior e UFRJ/Apex-Brasil.

tabilidade, o $I I M_{t}^{i}$ alcança um patamar de $20 \%$ em agosto de 2008, último mês antes dos movimentos irregulares provocados pela depreciação do Real em frente ao dólar estadunidense. Oportuno destacar que idêntico coeficiente foi obtido em dezembro de 2009. Após este último mês, caracteriza-se uma dinâmica de expansão, significativa, do $I I M_{t}^{i}$ da IT-AB, de modo que em agosto de 2010 chega-se a um patamar de $22 \%$.

Os próximos gráficos ajudam a entender os movimentos de $I I M_{t}^{i}$ e $C E X_{t}^{i} \mathrm{da}$ IT-AB. O Gráfico 4 se divide em duas partes. A parte (A) especifica três indicadores: o primeiro é o número índice $(2004 / \mathrm{I}=100)$ da demanda interna $(\mathrm{DI}) \mathrm{da}$ economia brasileira com ajuste sazonal e a preços constantes do primeiro trimestre de $2004^{10}$. O segundo indicador é o número índice $(2004 / \mathrm{I}=100)$ do quantum exportado de manufaturas com ajuste sazonal pela economia brasileira (ExQ). Por fim, o terceiro indicador é a taxa de câmbio nominal do dólar estadunidense em termos do Real brasileiro ${ }^{11}$. Já a parte (B), desta mesma figura, apresenta a diferença entre a taxa de crescimento da demanda interna a preços constantes e

\footnotetext{
${ }^{10}$ A demanda doméstica ou interna é definida como a soma dos dispêndios realizados pelas famílias (consumo das famílias), pelas empresas (investimento) e pelo governo (consumo do governo). Para o computo da DI não se considerou o valor de variação de estoques, componente do investimento, mas, somente, a formação bruta de capital fixo.

${ }^{11}$ Assume-se que a taxa de câmbio nominal é referência básica utilizada pelos empresários quando da aferição da rentabilidade relativa das vendas realizada no mercado doméstico vis-à-vis o mercado externo.
} 
do quantum exportado do Brasil, dois agregados caracterizados em número índice na parte (A) da mesma figura.

Gráfico 4: Demanda interna a preços constantes (2004/I=100), quantum exportado (2004/I=100), taxa de câmbio nominal (R\$/US\$) e diferença em pontos percentuais entre as taxas de crescimento da demanda interna a preços constantes e do quantum exportado - 2004/I a 2010/II
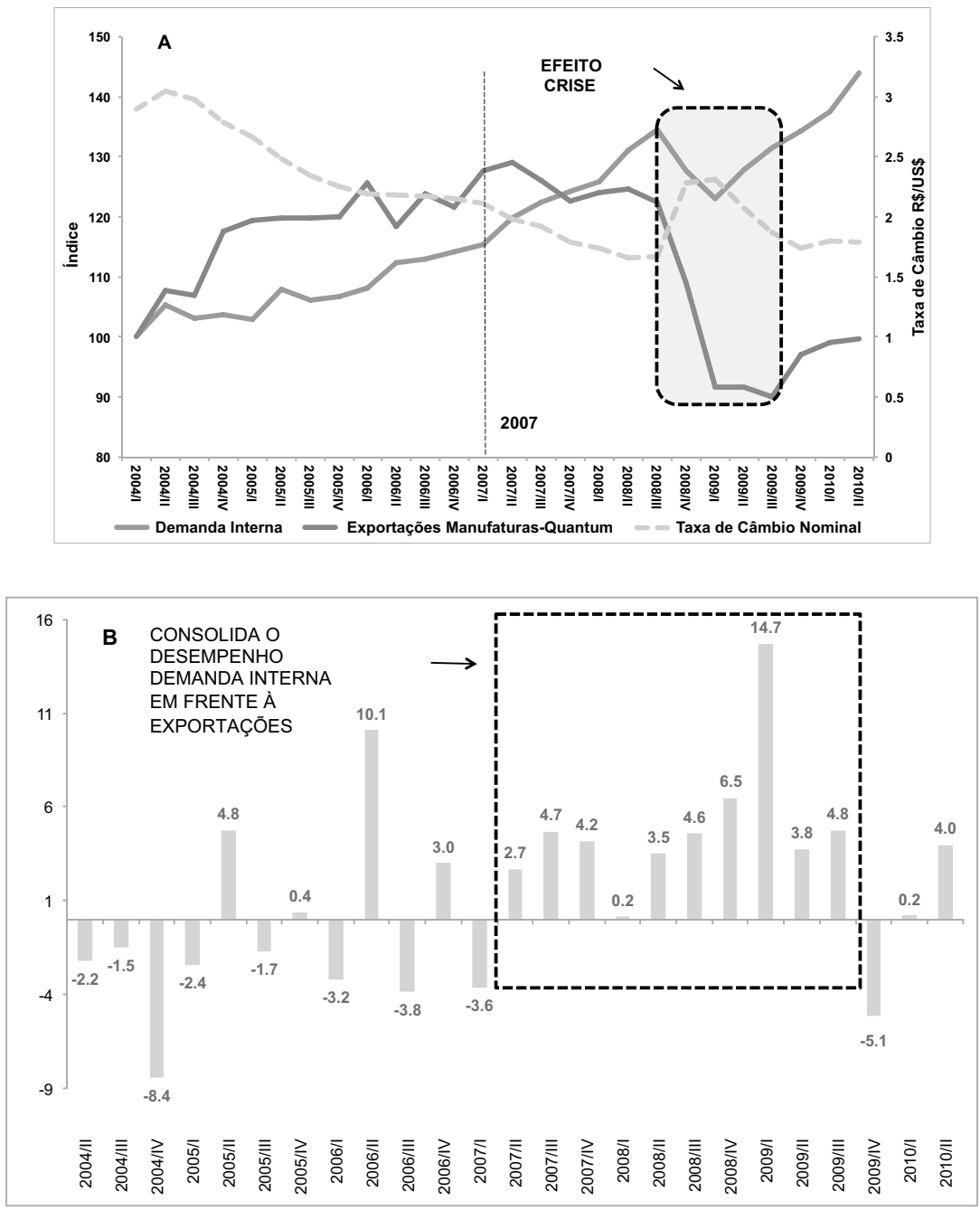

Fonte de dados brutos: Instituto Brasileiro de Geografia e Estatística (IBGE); Banco Central do Brasil (BCB) e Fundação Centro de Estudos de Comércio Exterior (FUNCEX).

Na parte (A) do Gráfico 4, nota-se o crescimento expressivo da demanda interna brasileira até o quarto trimestre de 2008. A partir deste ponto há contração de $5,1 \%$, o que identifica os efeitos da crise financeira global. Entretanto, já no segundo trimestre de 2009, retorna-se à trajetória de taxas positivas, sendo que, no 
segundo trimestre de 2010 o nível de DI se revela superior ao observado antes da crise. Ao comparar a dinâmica da DI e das ExQ observa-se que as ExQ cresceram, em média, a taxas superiores à DI até praticamente 2007. Concomitantemente, há evidências de um contínuo processo de apreciação do Real ante o dólar estadunidense desde o segundo trimestre de 2004. Isto é, mesmo com a queda na relação da moeda nacional com a moeda de troca internacional, as ExQ apresentavam um desempenho superior ao da DI. A partir de 2007 ocorre uma inversão nessa tendência, a DI eleva-se de forma consistente, enquanto as ExQ alternam trimestres de queda e estabilidade. Com a chegada da crise econômica de 2009, os desempenhos se distanciam definitivamente, de tal forma que somente a partir do quarto trimestre de 2009 percebem-se taxas de crescimento positivas das ExQ. O descasamento entre a taxa de crescimento da DI e das ExQ é destacado na parte (B) do Gráfico 4, através da diferença entre suas taxas de crescimento. Um valor positivo indica que o crescimento de DI é maior que o das ExQ. Entre o segundo trimestre de 2004 e o primeiro trimestre de 2007 há situações em que as ExQ crescem acima da DI e momentos em que ocorre o contrário, mas a trajetória é amplamente favorável às ExQ. Porém, a partir do início de 2007 há uma sequência de dez trimestres em que a taxa de crescimento da DI foi superior à das ExQ, com uma diferença que chegou a mais de 14 p.p. no início de 2009.

Por consequência, não é de causar surpresa que o coeficiente de exportação da IT-AB consolida trajetória de queda a partir de 2007, uma vez que se materializa robusto crescimento da DI e, ao mesmo tempo, contínuo processo de apreciação da moeda nacional. Isto é, a rentabilidade das exportações torna-se menor e o ambiente interno da economia brasileira é francamente positivo. Em conjunto, tais movimentos autorizam a formulação da seguinte hipótese: as empresas que atuam no Brasil se veem pressionadas a direcionar parcela maior da produção para o mercado interno, originando uma queda no coeficiente de exportação.

O Gráfico 5 possibilita uma melhor compreensão do $I I M_{t}^{i}$ da IT-AB, uma vez que especifica, na parte $(\mathrm{A})$, o número índice da produção física da indústria de transformação e o número índice do quantum importado total (ImQ) pelo Brasil, ambos apropriados na forma de médias móveis de 12 meses $^{12}$. A parte (B) apresenta as taxas de crescimento e as suas tendências para os indicadores expostos na parte (A) da mesma figura. Verifica-se uma relação positiva entre a produção da IT e o ImQ, ou seja, aumentos no nível da atividade da economia brasileira elevam o quantum importado. Um indicador quantitativo que mede a sensibilidade das ImQ, dada uma alteração na produção da IT, é a elasticidade ${ }^{13}$. Com efeito,

\footnotetext{
12 A média móvel dos dois indicadores teve como base séries dos seus números-índice com base fixa. Para o caso da produção da indústria de transformação estabeleceu-se $2002=100$ e para o quantum importado a base foi $2006=100$.

${ }^{13}$ A elasticidade de curto prazo é definida quando se captura o impacto das alterações após um ano; já a elasticidade de longo prazo é estabelecida ao se utilizar um modelo estatístico que necessita de, no mínimo, 30 anos. Assim, como se trabalha com média móvel de 12 meses dentro de períodos de seis e
} 
a elasticidade da produção da IT — quantum importado, que mede as variações na quantidade importada quando ocorre uma variação na produção da IT para o primeiro período destacado, ainda nos anos 1990, é de aproximadamente 3. Isto é, a cada $1 \%$ de aumento da produção da IT ocorria uma elevação média de $3 \%$ no ImQ. Por sua vez, para o segundo período assinalado, que considera os trimestres atuais de crescimento da economia brasileira, o valor da elasticidade aproximou-se de 1,7. É interessante salientar que esse comportamento elástico das importações em frente às alterações na atividade econômica do Brasil é identificado em vários outros trabalhos que tratam especificamente desse tema ${ }^{14}$, estabelecendo um comportamento da estrutura econômica brasileira como "crescimento com restrição externa”.

\section{Gráfico 5: Índices e taxas de crescimento (\%) da produção física da indústria de transformação brasileira e do quantum \\ importado — dezembro de 1991 a agosto de 2010}

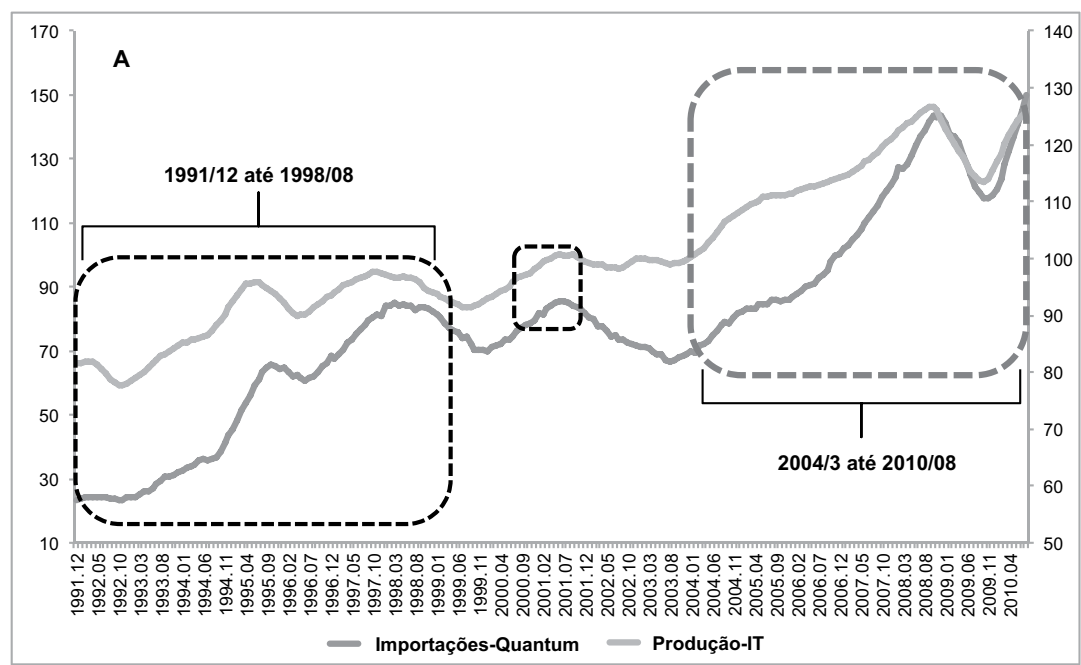

sete anos, calcula-se uma elasticidade mais de médio prazo, computada a partir das médias de crescimento dos dois indicadores analisados.

${ }^{14}$ Ver Zini Jr. (1988); Azevedo e Portugal (1998); Souza (2007); Santos, Sousa, Tejada e Jacinto (2009), entre outros. Um dos possíveis motivos para a diferença das elasticidades nos dois períodos é identificado ao se perceber que no início dos anos 1990 se estabelece a liberalização comercial no Brasil. Com uma conjuntura de fortalecimento da moeda nacional similar à atual, ainda que numa situação de crescimento econômico menos robusto, ocorre um expressivo aumento de importações, justificando uma elasticidade maior no primeiro período delimitado. A seguir, parece que a indústria nacional ajustou-se ao choque da liberalização comercial, diminuindo a elasticidade-produção da IT — quantum importado, posicionando-se em uma situação mais competitiva em situações de crescimento da produção e moeda nacional sobrevalorizada. 


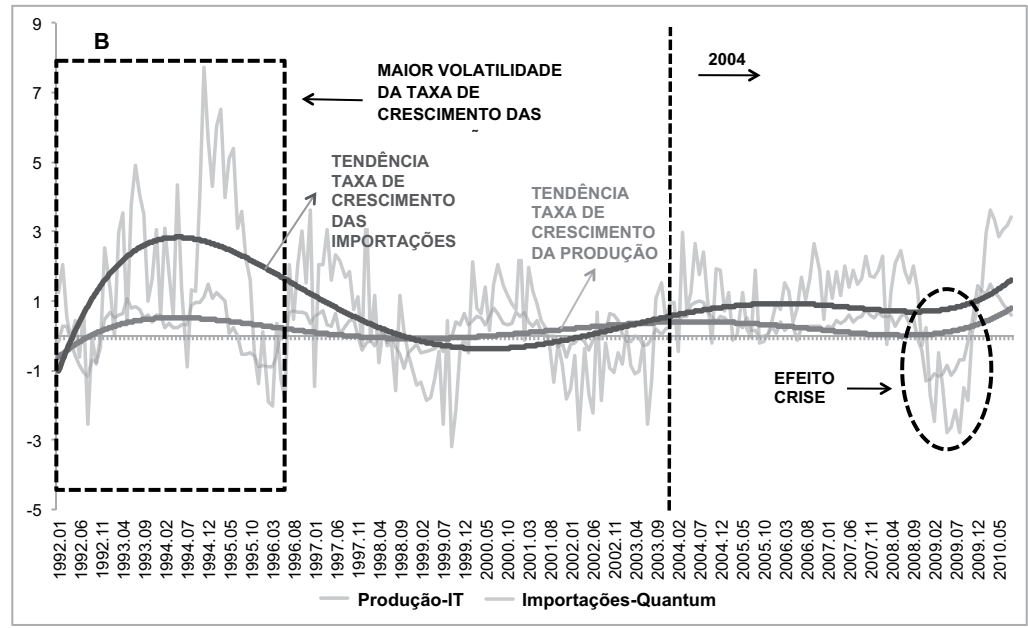

Fonte de dados brutos: Instituto Brasileiro de Geografia e Estatística (IBGE) e Fundação Centro de Estudos de Comércio Exterior (FUNCEX).

Outra maneira de analisar a relação entre o crescimento da produção da IT e o ImQ é a partir da parte (B) do Gráfico 5. Compara-se a taxa de crescimento dos dois indicadores analisados através da trajetória das suas tendências. Com isso, é possível notar que a maior volatilidade da taxa de crescimento das ImQ ocorre nos anos 1990, tal que a diferença entre essa taxa e a taxa de crescimento da produção da IT é significativamente maior que a atingida após 2004, momento em que se inicia um constante crescimento econômico no Brasil. Esse padrão de relação entre as duas taxas confirma os valores da elasticidade da produção da IT - quantum importado.

\section{A hipótese da desindustrialização via comércio exterior}

Este item procura verificar se a economia brasileira estaria experimentando a reprodução de um problema já visto no passado, qual seja, o caráter contracíclico dos saldos comerciais ${ }^{15}$, especialmente em produtos manufaturados. Acredita-se que o forte crescimento da demanda interna, a baixa rentabilidade das exportações e um ambiente econômico internacional incerto levaram ao deslocamento de parte da produção doméstica anteriormente exportada para o mercado interno. Ao mesmo tempo, a demanda interna brasileira possibilita níveis de produção física da indústria nacional em patamares historicamente altos, sendo que a estrutura da economia doméstica estabelece um crescimento das importações a taxas superiores

\footnotetext{
${ }^{15}$ A questão da tendência de deterioração das contas externas nos ciclos de expansão da demanda doméstica, caracterizando um padrão anticíclico dos saldos comerciais, tem sido um tema central na análise da evolução da economia brasileira. Ver, por exemplo, Michel e Carvalho (2009), Bresser-Pereira (2010) e IPEA (2010).
} 
às da produção. Assim, cresce a diferença entre as taxas de crescimento das exportações e das importações de bens industrializados, proporcionando uma dinâmica deficitária na balança comercial da indústria de transformação.

Para tanto, o método utilizado foi um modelo estatístico de correção de erro vetorial (VEC). As séries econômicas utilizadas nesse exercício são, basicamente, as apresentadas nas seções anteriores: exportações quantum de manufaturados (EXt); importações quantum totais (IMt); produção física da indústria de transformação (PROt); taxa de câmbio efetiva dividida pelo salário $(\mathrm{CAt})^{16}$; e atividade econômica (AEt). A periodicidade dessas séries é mensal, de janeiro de 2005 até agosto de $2010^{17}$. Ao se utilizar a periodicidade mensal elevam-se os graus de liberdade das estatísticas calculadas, definindo parâmetros mais robustos. É importante salientar que todas as variáveis empregadas sofreram ajuste sazonal e estão especificadas em logaritmo. Por simplificação, serão apresentadas aqui ${ }^{18}$ somente as interpretações econômicas e os resultados do Teste de Causalidade de Granger (TCG) e da Função Impulso-Resposta (FIR).

O primeiro teste a ser realizado é o TCG ${ }^{19}$ reportado na Tabela 1. É necessário salientar que o número de defasagens aplicada nesse teste foi de 2 , a mesma quantidade empregada no VEC $(2)^{20}$. Destaca-se a relação que a variável CAt tem com as outras variáveis endógenas do $\operatorname{VEC}(2)$ estimado. Rejeita-se a hipótese de que as variações em CAt não causam, no sentido de Granger, as variações na PROt e no $\mathrm{AEt}$, não rejeitando, no sentido causal de Granger, quando se toma a relação inver$\mathrm{sa}^{21}$. Ou seja, o sentido de causa vai das alterações no CAt em direção às mudanças em PROt e AEt. Ademais, ao se estabelecer um nível de significância de 5\%, outras relações de causalidade que são estatisticamente significativas envolvem as variáveis AEt e PROt. Rejeita-se a hipótese de que alterações em AEt não causam variações

\footnotetext{
${ }^{16}$ A correlação entre a taxa de câmbio efetiva dividida pelo salário e a taxa de câmbio nominal é igual a 0,953 . Isto é, seus movimentos tendenciais são praticamente iguais.

${ }^{17}$ A AEt teve como fonte o Banco Central, mais precisamente o seu indicador de atividade econômica (IBC-Br), utilizada como proxy da demanda interna. As outras variáveis tiveram como fonte: IBGE, FUNCEX e IPEA.

${ }^{18}$ Por falta de espaço omitimos os testes estatísticos que fundamentam a estrutura do VEC e o detalhamento dos procedimentos econométricos. Estes podem ser disponibilizados mediante solicitação por e-mail.

${ }^{19} \mathrm{O}$ Teste de Causalidade de Granger utilizado neste trabalho refere-se à relação de curto prazo. Para maiores detalhes ver Carneiro (1997).

${ }^{20}$ O VEC com duas defasagens e com cinco defasagens apresentaram resíduos não correlacionados. Pela estatística de Akaike a melhor estrutura é definida com duas defasagens, já pela estatística de Schwarz a melhor formatação seria com cinco defasagens. No entanto, ao levar em conta o número de graus de liberdade, estabeleceu-se que a estrutura com duas defasagens é a ideal. As informações sobre os Critérios de Akaike e Schwarz e o teste de autocorrelação residual Multiplicador de Lagrange VEC(2) podem ser solicitados por e-mail.

${ }^{21}$ A partir daqui todas as relações de causalidade são definidas no sentido de Granger. Por isso, omite-se a ênfase de Granger no texto.
} 
em IMt e, também, rejeita-se que as variações em PROt não causam modificações em IMt. Observa-se que não é possível rejeitar a causalidade contrária. Com isso, os testes estatísticos aqui empregados permitem duas observações: (i) o nível de atividade e a produção da economia brasileira definem o quantum importado; e (ii) não foi possível estabelecer uma relação causal robusta entre a evolução do comércio exterior e o desempenho da produção industrial nos termos usualmente sugeridos pela hipótese da desindustrialização via comércio exterior. Esta sugere que as alterações em IMt deslocariam a PROt. Ou seja, as IMt estariam causando, em parte, os movimentos da PROt. Porém, pelo teste de causalidade observa-se o sentido inverso, já que as alterações da PROt causam os movimentos das IMt.

\begin{tabular}{|c|c|c|}
\hline Hipótese Nula & Estatística-F & p-valor \\
\hline$\triangle P R O$ não causa $\triangle \mathrm{AE}$ & 1,9227 & 0,1551 \\
\hline$\triangle \mathrm{AE}$ não causa $\triangle \mathrm{PRO}$ & 0,5882 & 0,5612 \\
\hline$\Delta E X$ não causa $\triangle \mathrm{AE}$ & 0,3705 & 0,6919 \\
\hline$\triangle A E$ não causa $\triangle E X$ & 2,6670 & 0,0778 \\
\hline$\Delta \mathrm{IM}$ não causa $\triangle \mathrm{AE}$ & 3,0030 & 0,0572 \\
\hline$\triangle \mathrm{AE}$ não causa $\triangle \mathrm{IM}$ & 14,857 & 0,0000 \\
\hline$\triangle \mathrm{CA}$ não causa $\triangle \mathrm{AE}$ & 4,4026 & 0,0164 \\
\hline$\triangle \mathrm{AE}$ não causa $\triangle \mathrm{CA}$ & 0,8158 & 0,4471 \\
\hline$\triangle E X$ não causa $\triangle P R O$ & 0,1942 & 0,8240 \\
\hline$\triangle P R O$ não causa $\triangle E X$ & 2,3152 & 0,1075 \\
\hline$\triangle \mathrm{IM}$ não causa $\triangle \mathrm{PRO}$ & 1,3123 & 0,2768 \\
\hline$\triangle \mathrm{PRO}$ não causa $\triangle \mathrm{IM}$ & 8,6248 & 0,0005 \\
\hline$\triangle \mathrm{CA}$ não causa $\triangle \mathrm{PRO}$ & 6,6318 & 0,0025 \\
\hline$\triangle P R O$ não causa $\triangle C A$ & 0,1169 & 0,8899 \\
\hline$\Delta I M$ não causa $\Delta E X$ & 0,0113 & 0,9887 \\
\hline$\Delta \mathrm{EX}$ não causa $\Delta \mathrm{IM}$ & 1,3382 & 0,2712 \\
\hline$\triangle \mathrm{CA}$ não causa $\triangle \mathrm{EX}$ & 0,6261 & 0,6191 \\
\hline$\Delta \mathrm{EX}$ não causa $\triangle \mathrm{CA}$ & 0,4834 & 0,5381 \\
\hline$\Delta C A$ não causa $\triangle I M$ & 2,6899 & 0,0761 \\
\hline$\triangle \mathrm{IM}$ não causa $\triangle \mathrm{CA}$ & 0,3109 & 0,7339 \\
\hline
\end{tabular}

Nota: estatísticas calculadas pelo programa Eviews 5.0.

Ao se considerar a relação entre PROt e EXt, percebe-se que a probabilidade de não se rejeitar que as variações em EXt não causam alterações em PROt chega a $82,4 \%$. Já a probabilidade de não se rejeitar que as variações na PROt não causam mudanças em EXt é de 10,7\%. Por consequência, tem-se uma probabilidade maior para que os movimentos de PROt definam as alterações de EXt. Delimitado 
o comportamento de causalidade, no sentido de Granger, de algumas variáveis do modelo construído, parte-se à análise da função impulso-resposta (FIR).

A FIR revela o comportamento das variáveis endógenas do sistema de equações estimado, dado um choque exógeno em uma das variáveis deste mesmo sistema. Isto é, dado um impulso em uma determinada variável endógena presente no VEC(2), esta mudança não se propaga somente em uma direção, mas afeta todas as outras variáveis endógenas do modelo através de uma dinâmica interna de defasagens $^{22}$.

Partindo de um total de 16 funções impulso-resposta, decidiu-se apresentar 10 funções. Essa decisão foi pautada pelos testes de causalidade de Granger desenvolvidos anteriormente. Nas relações em que não se obteve uma significância estatística pronunciada, optou-se pela demarcação teórica da correspondência de causa. Adicionalmente, priorizou-se, na exposição do conjunto de funções impulso-resposta, a adequação ao objetivo desse trabalho. O Gráfico 6 identifica as funções destacadas no $\operatorname{VEC}(2)$ estimado.

É importante notar o comportamento da PROt após um impulso no AEt e, ao mesmo tempo, o mesmo movimento de PROt após um choque em EXt. A parte (A) do Gráfico 6 mostra o efeito resposta de uma variação exógena (de um desvio-padrão) na equação da AEt sobre a PROt. Uma alteração na AEt resulta em rápido ajuste da PROt, que eleva a produção física de forma duradoura. Por sua vez, um impulso na equação da EXt determina, também, uma elevação na PROt (parte B). Todavia, a elevação de PROt após um impulso na AEt é, em média, praticamente três vezes maior do que a resposta de PROt após um choque nas EXt ${ }^{23}$. Por consequência, a produção física da indústria de transformação no Brasil reage de forma mais acentuada às alterações na demanda interna vis-à-vis os movimentos do quantum exportado de manufatura. Em síntese, no período considerado, evidencia-se uma resposta vigorosa da PROt às variações de AEt, alterando de maneira permanente o nível desse componente endógeno do $\mathrm{VEC}(2)$ estimado. O mesmo resultado ocorre com tal intensidade na relação entre PROt e EXt, o que nos remete à

\footnotetext{
${ }^{22}$ Esse impulso é estabelecido pela variação de um desvio-padrão no resíduo estimado da equação de uma determinada variável endógena. A FIR mostra os efeitos de um choque temporário em $1^{\text {a }}$ diferença, que por sua vez torna-se uma mudança permanente no nível. Assim, é importante conhecer as grandezas dessas mudanças, tanto do ponto de vista temporal, quanto em termos de sua amplitude. Salienta-se, ainda, que o ordenamento das equações de curto prazo irá afetar a FIR. Isto é, se ao construir o exercício de impulso-resposta se adicionar como primeira equação do sistema as EXt, estar-se-á depositando um peso maior nesta variável vis-à-vis os outros componentes endógenos do VEC(2). Todavia, segundo Pesaran e Shin (1998), os resultados do teste de impulso-resposta, formatados tendo como base o impulso generalizado, independem de como as equações das variáveis endógenas estão ordenadas. Com base nisto, decidiu-se compor a função impulso-resposta partindo do impulso generalizado.

${ }^{23}$ Por falta de espaço omitimos a tabela com os valores da função impulso-resposta que podem ser disponibilizados mediante solicitação por e-mail. De acordo com o exercício proposto, tomando-se a média para dez períodos dos efeitos de impulso-resposta, verifica-se que um impulso das Ext gera uma resposta da PROt de 0,00750 e um impulso da AEt gera uma resposta da PROt de 0,02226.
} 

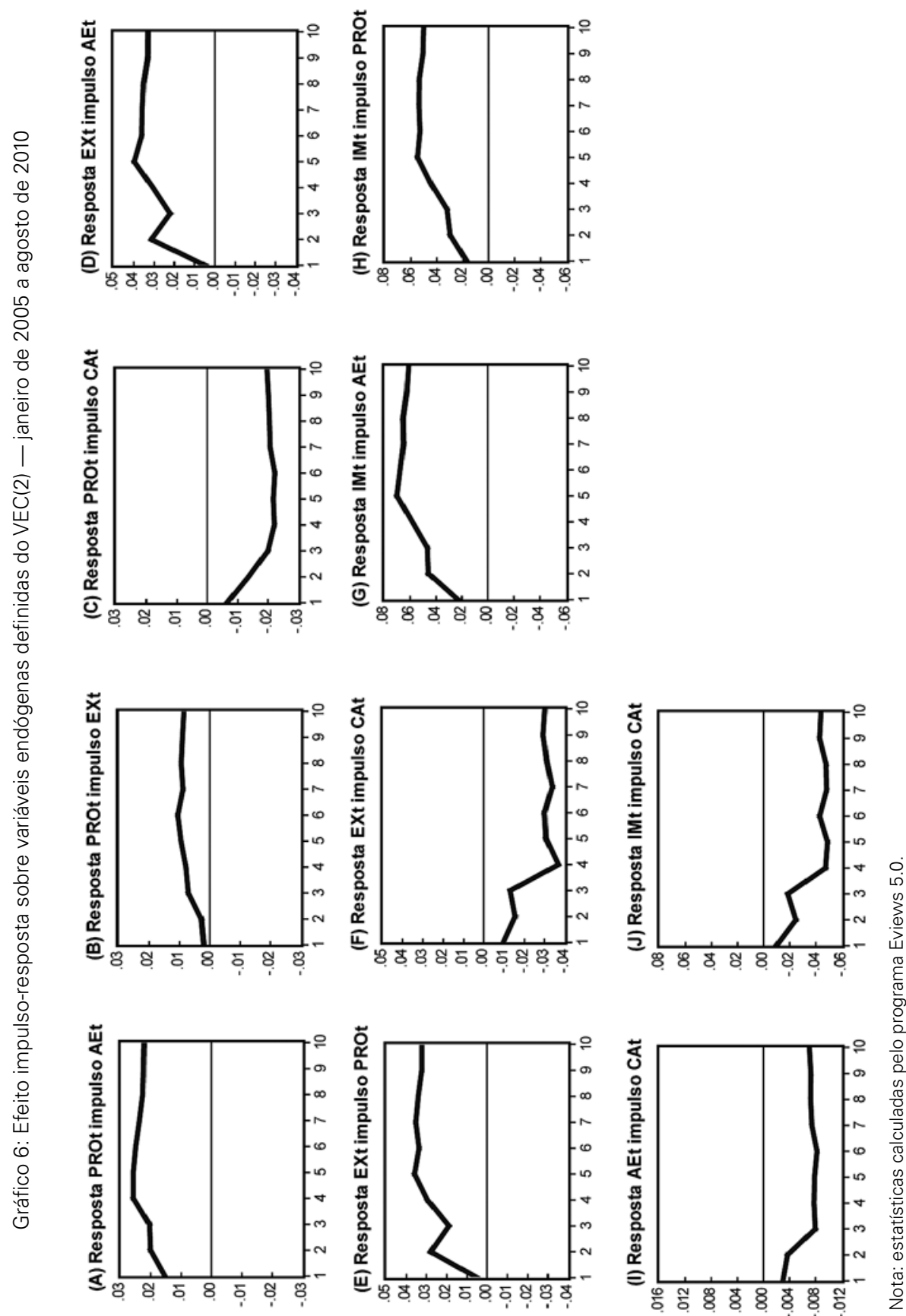
hipótese aqui delineada de que as empresas tendem a direcionar a produção nacional para o mercado interno, quando este revela forte expansão, em detrimento do mercado internacional.

Com respeito às relações entre IMt e AEt, bem como entre IMt e PROt, em que a causalidade observada, no sentido de Granger, é das duas últimas para a primeira (Tabela 1), tem-se que um impulso na AEt gera uma resposta positiva e permanente nas IMt (parte G). No mesmo sentido, um impulso na PROt induz a uma mudança consistente nas IMt (parte $\mathrm{H}$ ). Com isso, ao estabelecer que uma alteração positiva na PROt gera alterações no mesmo sentido nas EXt (parte E) e nas IMt é indispensável verificar o resultado, esperado, no saldo da balança comercial de manufatura. Ainda observando as funções impulso-resposta, é possível identificar que um choque na PROt gera uma elevação maior nas IMt que nas $\mathrm{EXt}^{24}$. Isto cria a possibilidade de que o incremento na produção industrial gere déficits comerciais no setor manufatureiro $^{25}$. Isto é, assinala-se para o problema de restrição externa ao crescimento da PROt.

É importante explicitar os resultados da FIR do CAt sobre IMt, EXt, PROt e AEt, lembrando que a relação causal, no sentido de Granger, identificada na Tabela 1 foi do CAt para AEt e PROt. Assim, encontrou-se uma resposta negativa nos movimentos das EXt após um impulso no CAt (parte F). As variações nas IMt relacionadas a um choque no CAt (parte J) são mais expressivas que nas EXt. Por fim, obtém-se respostas similares ao encontrado para as EXt, para PROt e para AEt, em função de impulsos no CAt. Define-se, com isso, uma queda nesses três componentes endógenos do $\operatorname{VEC}(2)$, sendo que esse resultado torna-se estável, não proporcionando um retorno ao valor inicial. Ou seja, uma depreciação da moeda nacional em frente ao dólar estadunidense causaria quedas na AEt, nas EXt e na PROt. Sugere-se aqui uma possível explicação para este comportamento, que se fundamenta pela natureza período analisado, em que os recorrentes choques externos derivados da instabilidade no ambiente internacional, particularmente após 2008, foram absorvidos, em um primeiro momento, pela taxa de câmbio, para, na sequência, afetarem as varáveis reais, como produção industrial, nível de atividade e quantidade física exportada. Por isso, acredita-se que as funções impulso-resposta dessas três variáveis são explicadas mais pela crise econômica de 2009 do que por uma alteração no CAt.

De modo a avaliar o comportamento destas relações, considerando-se os coeficientes de exportações e de penetração de importações, construiu-se outro modelo VEC, denominado VECcof. Foram utilizadas as mesmas variáveis anteriormente definidas, porém com a substituição de EXt pelo coeficiente de exportações (CEXt) e de IMt pelo índice de penetração das importações (IIMt). O número ideal

\footnotetext{
${ }^{24}$ Tomando-se a média para dez períodos dos efeitos de impulso-resposta, verifica-se que um impulso da PROt gera uma resposta das IMt bem maior $(0,04380)$ que a resposta das Ext $(0,02843)$.

${ }^{25}$ É sempre bom lembrar que tal resultado dependerá da evolução dos preços dos bens exportados e importados, na medida em que o exercício considera somente as respectivas quantidades.
} 
de defasagens é 2 (VECcof $(2))^{26}$. O Gráfico 7 mostra, na função resposta do CEXt após um impulso na PROt, uma queda no coeficiente analisado. Ao mesmo tempo, um choque positivo na AEt apresenta, também, uma diminuição no CEXt, mas este coeficiente retorna ao seu valor inicial depois de 6-7 meses.

Gráfico 7: Efeito impulso-resposta sobre variáveis endógenas definidas no VECcof(2) — janeiro de 2005 a agosto de 2010
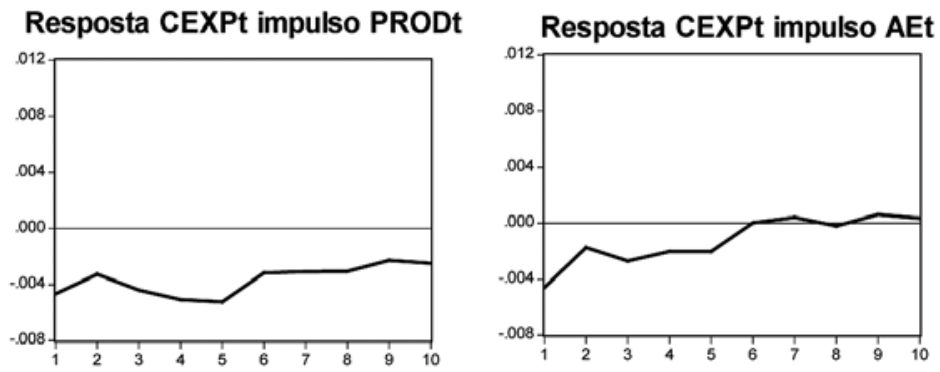

Nota: estatísticas calculadas pelo programa Eviews 5.0.

A partir destes exercícios, sugere-se relevante a interpretação de que, no período analisado, a ampliação do mercado doméstico brasileiro, a baixa rentabilidade das exportações e as incertezas no comércio internacional induziram a indústria nacional a direcionar parcela maior da sua produção para atender à demanda interna. Por isso, a partir de 2007 verifica-se uma tendência de queda duradoura no coeficiente de exportação da indústria de transformação sem alimentos e bebidas (IT-AB), o que perdura até 2010 (Gráfico 3). Por sua vez, praticamente no mesmo período, terceiro trimestre de 2006, caracteriza-se uma alteração de estável para decrescente na tendência estimada do saldo comercial da IT-AB. Isto é, uma parcela do déficit comercial da IT-AB é explicada pela opção das empresas em voltarem-se mais para o mercado interno. Por esse motivo, assume-se aqui que a simples observação desse saldo comercial não é condição suficiente para identificar a existência de uma trajetória de desindustrialização via comércio exterior. Adicionalmente, essas condições favoráveis de expansão da demanda interna e de estabilidade de preços não foram observadas no Brasil desde a liberalização comercial, particularmente a partir do início dos anos 1990. A conjuntura propícia de crescimento da renda doméstica, por sua vez, pressiona positivamente as taxas de crescimento dos bens importados, identificada na elevação do índice de penetração da IT-AB, principalmente após 2006 . O crescimento das importações a taxas superiores às da produção segue o padrão estrutural da economia nacional, percebendo-se que a indústria nacional reagiu de forma positiva depois de 2004, quando compa-

\footnotetext{
${ }^{26}$ Por falta de espaço, os testes de estabilidade e de cointegração não foram incluídos no artigo, mas podem ser solicitados para os autores por e-mail.
} 
rada ao período imediatamente seguinte à liberalização comercial, principalmente entre 1992 e 1996 (Gráfico 5, parte B).

O robusto e constante crescimento da demanda interna, no período em foco, elevou a produção e a utilização da capacidade instalada da indústria doméstica a níveis não observados historicamente. Esse desempenho levou à necessidade de ampliação da capacidade instalada da indústria, causando um aumento da importação de bens de capital, especialmente em 2010. Com efeito, um dos fatores de elevação do coeficiente de penetração de importações da IT-AB, nesse ano, foi a significativa importação de bens de investimento feita pelas empresas brasileiras. Ao mesmo tempo, a produção da indústria nacional de bens de capital também acaba por crescer a taxas recordes, atingindo marcas de produção não contempladas nos últimos 25 anos e operando em condições próximas do pleno emprego desde o terceiro trimestre de 2006.

Neste contexto, alguns subsetores da economia brasileira merecem especial atenção, principalmente os subsetores têxteis e de vestuário/confecções. Ao se comparar a produção desse último subsetor, entre janeiro e agosto de 2004 e o mesmo período de 2010, encontra-se uma taxa de crescimento praticamente nula. Por sua vez, o índice de penetração de importações passou de 4,8\% em 2005 para $11 \%$ nos oito primeiro meses de 2010, sendo que essa taxa se alterou paulatinamente, sem grandes mudanças em 2010. Já a produção dos subsetor têxtil, entre janeiro e agosto de 2004 e o mesmo período em 2010, cresceu apenas 2,5\%, ao passo que seu índice de penetração de importações atingiu, nos primeiros oito meses de 2010, um valor de 19,1\%, saindo de um percentual de 10,1 em 2005.

Cabe, ainda, alertar para a significativa queda no coeficiente de exportações da IT-AB. Isso porque, conforme explanação anterior, uma parcela do déficit da balança comercial da IT-AB é causada pela queda no coeficiente de exportação da indústria nacional. Rowthorn e Wells $(1987$, p. 37) sugerem que a razão entre as exportações líquidas de manufaturas e o PIB é mais importante que a relação entre emprego industrial e emprego total da economia, quando se quer verificar uma trajetória de desindustrialização. Ou seja, se o objetivo é elevar o coeficiente de exportações da indústria de transformação e não apenas o valor exportado dessa indústria, é fundamental a adoção de medidas voltadas para alterações estruturais na economia brasileira.

\section{CONSIDERAÇÕES FINAIS}

O presente artigo teve como objetivo observar a marcha do saldo comercial brasileiro no contexto de recuperação de maior dinamismo da economia brasileira nesta primeira década do século XXI. Em vários momentos do processo de modernização produtiva do Brasil, os ciclos de aceleração do crescimento vieram acompanhados de deterioração das contas externas. A elevada elasticidade das importações e a tendência de direcionamento da produção industrial para o mercado doméstico interagiam no sentido de deteriorar a balança comercial, especialmente no segmento de manufaturas. Entre 2004 e 2008, verificou-se a intensificação da expansão da 
demanda doméstica, em seus diversos componentes, e uma deterioração crescente dos saldos comerciais. A balança comercial de produtos manufaturados tornou-se deficitária. Neste contexto, ampliou-se o debate em torno dos riscos de desindustrialização. Nossa análise procurou contribuir com evidências potencialmente originais, a partir de um amplo conjunto de evidências empíricas e testes econométricos.

Nossas principais conclusões foram: (i) há fortes indícios de que o período recente reproduziu o quadro de aceleração do crescimento com deterioração da balança comercial em função da estratégia privada de direcionamento da produção industrial para o mercado interno; e (ii) não encontramos evidências suficientemente robustas de que o comércio internacional esteja induzindo a um processo de desindustrialização. Vale dizer, o principal problema detectado é a queda nos coeficientes de exportação. Tais constatações não afastam o risco de agravamento no quadro de desindustrialização, nos termos sugeridos por Oreiro e Feijó (2010), Bresser-Pereira (2010), Feijó e Lamonica (2012), dentre outros. Ademais, verificou-se mudança significativa no comportamento da sazonalidade da balança comercial, proporcionada, principalmente, pelas vendas de bens intensivos em recursos naturais ao mercado chinês e pela escalada da elevação dos preços das commodities no mercado internacional. Este cenário se aproxima da visão expressa em Bresser-Pereira (2010) sobre a existência de "doença holandesa" no Brasil.

Por conta disto, reforça-se a importância da elaboração de políticas públicas voltadas não só para o aumento das exportações, mas sim para a elevação da parcela exportada no total produzido pela indústria nacional. É pouco provável que medidas paliativas, que objetivam diminuir as importações, se configurem em condição suficiente para afastar o Brasil do risco de que o comércio exterior induza ao agravamento do processo de desindustrialização no futuro. Políticas industriais mais robustas e com foco na inovação tecnológica e ampliação dos coeficientes de exportação, respaldadas pela modernização da infraestrutura e redução das distorções macroeconômicas associadas aos níveis atuais das taxas de câmbio e juros, são complementos essenciais para garantir a manutenção de uma estrutura produtiva diversificada e moderna no futuro.

Por fim, salienta-se que as considerações e conclusões apontadas neste trabalho não esgotam as discussões sobre o tema de desindustrialização devido ao comércio exterior. Entretanto, acredita-se que este trabalho contribui para elucidar alguns movimentos intrínsecos à indústria nacional e sua relação com o comércio exterior em uma situação de forte aquecimento da demanda doméstica no Brasil após 2005 e, mais especificamente, após a crise econômica de 2009.

\section{REFERÊNCIAS BIBLIOGRÁFICAS}

AZEVEDO, A. F. Z.; PORTUGAL, M. S. Abertura comercial brasileira e instabilidade da demanda de importações. Nova Economia, Belo Horizonte, UFMG, v. 8, n. 1, p. 37-63, jul. 1998.

BONELLI, R.; PESSÔA, S. A. Desindustrialização no Brasil: um resumo da evidência. Rio de Janeiro: IBRE/Fundação Getulio Vargas, maio 2010. (Texto para Discussão n. 7).

BRESSER-PEREIRA, L. C. (org.). Doença holandesa e indústria. Rio de Janeiro: Editora FGV, 2010. 
CANUTO, O.; GIUGALE, M. (Editors). The day after tomorrow: a handbook on the future of economic policy in the developing world. Washington, DC: The World Bank, 2010.

CARNEIRO, F. G. A metodologia dos testes de causalidade em economia. Brasília: Departamento de Economia, UnB, 1997. (Série Textos Didáticos, n. 20).

CARNEIRO, R. Desenvolvimento em crise: a economia brasileira no último quarto do século XX. São Paulo: UNESP, 2002.

CASTRO, A. B., SOUZA, E. F. P. A economia brasileira em marcha forçada. Rio de Janeiro: Paz e Terra, 1985.

COMMANDEUR, J. J. F.; KOOPMAN, S. J. Practical econometrics: an introduction to state space time series analysis. Oxford: Oxford University Press, 2007.

FEIJÓ, C. A., LAMONICA, M. T. Importancia del sector industrial para el desarrollo de la economía brasileña. Revista de la Cepal, n. 107, agosto, p. 115-136. Santiago de Chile, Cepal, 2012.

FISHLOW, A.; BACHA. E. Recent commodity price boom and Latin American growth: more than new bottles for an old wine? In: José Antonio Ocampo and Jaime Ros (eds.). Handbook of Latin American Economics. Oxford University Press, 2010. Disponível em: http://iepecdg.com.br/uploads/artigos/0529TPD16_Bacha_Fishlow.pdf. Acesso em fevereiro de 2011.

FURTADO, C. M. Formação econômica do Brasil (Edição comemorativa dos 50 anos). São Paulo: Companhia das Letras, 2009.

HARVEY, A. C. Forecasting, structural time series models and the Kalman Filter. Cambridge: Cambridge University Press, 1989.

IEDI. A indústria de transformação por intensidade tecnológica: o desafio de crescer sem deteriorar ainda mais o saldo comercial. Carta IEDI, São Paulo, IEDI, n. 454, 11 de fevereiro de 2011.

IPEA. O Brasil em 4 décadas. Brasília, DF: Instituto de Pesquisa Econômica Aplicada, 2010. (Texto para Discussão, n. 1.500).

KALDOR, N. Causes of the slow rate of economic growth of the United Kingdom. An inaugural lecture. Cambridge: Cambridge University Press, 1966.

KALDOR, N. Strategic factors in economic development. Ithaca, NY: Cornell University, 1967.

LEVY, P. M.; SERRA, M. I. F. Coeficientes de importação e exportação na indústria. Boletim de Conjuntura, Rio de Janeiro, IPEA, n. 58, jul.-ago. 2002.

MICHEL, R.; CARVALHO, L. (Orgs.). Crescimento econômico: setor externo e inflação. Brasília, DF: Instituto de Pesquisa Econômica Aplicada, 2009.

MINISTÉRIO DA FAZENDA. A economia brasileira em perspectiva (várias edições). Brasília: Ministério da Fazenda, 2010. Disponível em: http://www.fazenda.gov.br/portugues/docs/perspectiva-economia-brasileira/link.htm. Acesso em fevereiro de 2011.

MOREIRA, M. M.; PUGA, F.P. Coeficiente de comércio em 2000: o desafio externo. Rio de Janeiro: BNDES, maio 2001. (Nota técnica AP/DEPEC n. 04/2001).

NASSIF, A. Há evidências de desindustrialização no Brasil? Revista de Economia Política, São Paulo, vol. 28, n. 1 (109), p. 72-96, jan.-mar. 2008.

NASSIF, A., C.; FEIJÓ, C.A., ARAÚJO, E. The long-term “optimal” real exchange rate and the currency overvaluation trend in open emerging economies: the case of Brazil. Discussion Paper, $\mathrm{N}^{\circ} 206$, December. Geneva, UNCTAD, 2011.

PALMA, G. Four sources of 'de-industrialisation' and a new concept of the 'Dutch Disease'. HSRC EGDI Roundtable, May, 2007.

OREIRO, J. L.; FEIJÓ, C. Desindustrialização: conceituação, causas, efeitos e o caso brasileiro. Revista de Economia Política, São Paulo, v. 30, n. 2 (118), p. 219-232, abr.-jun. 2010.

PESARAN, M. H; SHIN, Y. Generalized impulse response analysis in linear multivariate models. Economics Letters, vol. 58, p. 17-29, jan. 1998.

PREBISCH, R. The economic development of Latin America and its principal problems. New York, United Nations, 1950.

ROWTHORN, R. E.; WELLS, J. R. De-industrialization and foreign trade. Cambridge: Cambridge University Press, 1987. 
ROWTHORN, R; RAMASWANY, R. Growth, trade and deindustrialization. Washington, DC: International Monetary Fund, 1999. (IMF Staff Papers, v. 46, n. 1).

SANTOS, A. M. R.; SOUSA, E. A.; TEJADA, C. A. O.; JACINTO, P. A. elasticidade-preço das exportações e importações: uma abordagem através de dados em painel para os estados do Brasil. In: Encontro Nacional da Associação Brasileira de Estudos Regionais e Urbanos. São Paulo, 2009.

SOUZA, M. Liberação, importações e crescimento econômico na América Latina. 2007. Tese de Doutorado em Economia. Universidade de Brasília, Brasília, 2007.

TAVARES, M. C. Da substituição de importações ao capitalismo financeiro: ensaios sobre economia brasileira, 2. ed. Rio de Janeiro: Zahar, 1973.

ZINI Jr., A. A. Funções de exportação e de importação para o Brasil. Pesquisa e Planejamento Econômico, Rio de Janeiro, IPEA, v. 18, n. 3, p. 615-661, dez. 1988. 